Chapter 13

\title{
Occurrence of Organochlorine Pesticides Residues in Animal Feed and Fatty Bovine Tissue
}

\author{
S. Panseri, P.A. Biondi, D. Vigo, R. Communod and \\ L. M. Chiesa
}

Additional information is available at the end of the chapter

http://dx.doi.org/10.5772/54182

\section{Introduction}

Nowadays, more than 800 different kinds of pesticides are used for the control of insects, rodents, fungi and unwanted plants in the process of agricultural production. Although most of them leave the products or degrade in soil, water and atmosphere, some trace amounts of pesticide residues can be transferred to humans via the food chain, being potentially harmful to human health. [1] Pest control in intensive agriculture involves treatment of crops (fruits, vegetables, cereals, etc) pre and post harvest stages, rodenticides are employed in the post-harvest storage stage, and fungicides are applied at any stage of the process depending on the crop. These chemicals can be transferred from plant to animal via the food chain. Furthermore, breeding animals and their accommodation can themselves be sprayed with pesticide solution to prevent pest infestations. Consequently, both these contamination routes can lead to bioaccumulation of persistent pesticides in food products of animal origin such as meat, fat, fish, eggs and milk. [2,3] During the last decades much attention has been given to this group of substances and the international level after it became apparent that they are transported through the environment and critical concentrations have been reached in some areas even in places where they have never been produced or used. Several countries banned the use of Organochlorine Pesticides (OCPs) during the 1970s and 1980s, although many of them continue to been used by other countries. OCPs have been identified as one of the major classes of environmental contaminants because of their persistence, long-range transport ability and human and animal toxic effects. OCPs are carcinogenic in animals as well as in human (International Agency for Research on Cancer, 1987). The immunotoxicity of selected OCPs has been also documented in vitro [4], in vivo [5], as well as in animals, in human fetal, neonatal and infant immune systems $[6,7,8,9]$. 
A growing number of epidemiological studies have investigated blood or adipose levels of OCPs and their metabolites in relation with cancer, neurodevelopmental effects, immunotoxicity and reproductive efficiency $[10,11,12]$. The main sources of OCPs in the human diet are foods of animal origin and environmental exposure. It has been concluded that humans are exposed to toxic compounds via diet in a much higher degree compared to other exposure routes such as inhalation and dermal exposure. Low volatility and high stability, together with lipophilic behaviour, are responsible critical factor for their persistence in the environment (air, water and soil) and subsequent concentration in fatty tissues through the food chain. Therefore, it's important to identify and to monitor levels of OCPs in foodstuff of animal origin (meat and tissues that contain fat, milk and dairy products, eggs, honey and fish). The main pathway for the OCPs contamination of animal food is the ingestion of the contaminated food and/or water by the animals. $[13,14,15]$ Breeding animals can accumulate persistent organic pollutants from contaminated feed and water, and/or from pesticides application in livestock areas (treatment of cowshed, pigsties, sheepfold etc.). $[16,17,18]$ The use of feedstuffs in farms has become indispensable for animal diet in developed countries because of increasingly higher production requirements. Animal feed plays an important part in the food chain and has implication for the composition and quality of the livestock products that people consume. Therefore, the control of OCPs residues in animal feed is mandatory as well as the control in fatty tissues.

\subsection{Organochlorine Pesticides (OCPs)}

Organochlorine pesticides (OCPs) were intensively used in agriculture to protect cultivated plants in mid-twentieth century. 1,1,1-Trichloro-2,2-bis(4-chlorophenyl)ethane (DDT), one of the common OCPs, was used to prevent spreading of malaria and other vector-borne diseases such as dengue, leishmaniasis and Japanese encephalitis through the prevention of growth of mosquito.[19,20] After OCPs were used widely in soil and plants for some years and due to their relative stability and bioaccumulation property, these persistent chemicals can be transferred and magnified to higher trophic level through the food chain. Consequently, OCP residues are present in fatty foods, both foods of animal origin such as meat, eggs and milk, and of plant origin such as vegetable oil, nuts, oat and olives. Besides, these chemicals are widely distributed in the environment, which provides another route of unwanted intake in human. [21,22,23] Nevertheless, human exposure occurs still primarily via low level food contamination. Since their mode of action is by targeting system or enzymes in the pest which may be identical or very similar to system or enzymes in human beings, these OCPs pose risks to human health and the environment. [24,25] Thus, monitoring of OCPs residues in food becomes a routine analysis of pesticides monitoring laboratories. All US government pesticides datasets showed that persistent OCP residues were surprisingly common in certain foods despite being off the market for over 30 years. Residues of dieldrin, in particular, posed substantial risks in certain root crops. About one quarter of samples of organically labelled fresh produce contained pesticides residues, compared with about three quarters of conventional samples. [26,27] Among the contaminated organic vegetable samples, about $60 \%$ of them were contaminated with OCPs. After some OCPs were banned for use since the 80 s, common daily food items such as eggs, milk, poultry, meat and fish have 
been used for monitoring the residuals levels of OCPs. As regards food of animal origin, one efficient way to avoid large-scale contamination is to control and monitor the levels of OCPs residues present in animal feeds before being fed to the husbandry animals. $[28,29,30]$

At the same time, public health safety authorities should constantly monitor the OCPs in animal food commodities as the major source of human background exposure to OCPs is through food of animal origin. Most persistent organic pollutant (POPs) are OCPs, namely, aldrin, endrin, chlordane, DDT and hexachlorobenzene (HCB). They have been banned for agricultural or domestic use in Europe, North America and many countries of South America, in accordance with Stockholm Convention in 1980s. However, some OCPs are still used, e.g. DDT is used to control the growth of mosquito that spread malaria or as antifouling agent in some developing countries. [31,32] Residues of OCPs have been detected in breast milk (including DDT, $\mathrm{HCB}$ and $\mathrm{HCH}$ isomers) in contaminated areas. Recently, the scope of POPs was extended to include nine plus one chemicals. Among these new POPs, chlordecone, lindane, $\alpha-\mathrm{HCH}, \beta-\mathrm{HCH}$, pentachlorobenzene (PeCB) and endosulfan, also belong to OCPs. [33,34] In order to fulfil the requirements of the Stockholm convention, the participating countries have to develop their own implementation plant to monitor the background level and collate the exposure data. To ensure the pesticide residues are not found in food of feed at levels presenting an unacceptable risk for human consumption, maximum residue levels (MRLs) have therefore been set by the European Commission. [35,36,37] MRLs are the upper legal concentration limits for pesticides in or on food or feed. They are set for a wide range of food commodities of plant and animal origin, and they usually apply to the product as placed in the market. MRLs are not simply set as toxicological threshold levels; they are derived after a comprehensive assessment of the properties of the active substance and the residues behaviour on treated crops. Both the periodic estimation of human exposure to persistent organic pollutants and the establishment by the EU authorities of MRLs in foods have required the development of analytical methods suitable for research purposes and inspection programmes. As an example, the European Union has established maximum contents for these compounds in animal feed which can be as low as $5 \mu \mathrm{g} \mathrm{Kg}^{-1}$ for some OCPs in fish feed and $\beta-\mathrm{HCH}$ in cattle feed. In the rest of feed materials these values can be as low as $10 \mu \mathrm{g} \mathrm{Kg}-1$ relative to feedstuff with moisture content of $12 \%$. [38,39,40]

\subsection{Extraction methods and clean-up of OCPs}

Animal feed as well as animal fat are considered a very complex matrices with large number of components especially lipids. Consequently, the development od sensitive methods for its analysis with elimination of interferent compounds and enough efficiency in term of analyte recovery represents an interesting task. [41,42] The most intricate step in these procedures is represented by the sample extraction and clean-up that should be efficient enough to allow a reliable screening of contaminated samples. The selection of suitable solvent (s) and extraction method is critical for obtaining satisfactory recovery of OCPs from the food matrix. Of course, if co-extracted materials are minimised in the extract, the clean-up procedure would became simpler. Owing to the lipo- 
philicity of OCPs, organic solvent (s) normally can extract OCPs form food efficiently but lipids are also co-extracted. Solid-liquid extraction method was applicable for extracting OCPs from various types of food samples including vegetables, meats and its products, fish, eggs and animal fats. In addition, several standardised methods, including AOAC 970.52, EN 1528 and EN 12393, have employed such solid-liquid or liquid-liquid extraction techniques for the determination of OCPs in both fatty and non-fatty foods. $[43,44,45]$ In some occasions, sonication or Polytron was also applied to improve the extraction efficiency and recoveries.

\subsection{Clean-up methods}

Matrix constituents can be co-extracted and later co-eluted with analysed components and can consequently interfere with analyte identification and quantification. Moreover, co-extracted compounds, especially lipids, tend to adsorb in GC system such as injection port and column, resulting in poor chromatographic performance. A through clean-up minimised such matrix issues, improves sensitivity, permits more consistent and repeatable results, and extend the capillary column lifetime. Several approaches have been attempted to eliminated co-extracted interferences from extracts, including freezing centrifugation or filtration, liquid-liquid partitioning, gel permeation chromatography (GPC), solid phase extraction (SPE) and solid-phase microextraction (SPME). The simplest approach to remove the fatty co-extracted is by freezing centrifugation. [46,47] The logic behind is that fatty substances (mainly lipids) have lower melting point than the solvent so that frozen lipids can be removed by centrifugation or filtering while OCPs remain dissolved in the solvent. Different freezing temperatures ranged from $-24{ }^{\circ} \mathrm{C}$ to $-70{ }^{\circ} \mathrm{C}$ have been used. However, the solubility of lipids in solvent not only depends on the temperature but also the solubility product. Therefore this technique can remove significant amount of lipids for some food matrix but not for every matrix. Certain amount of lipids would remain in the solvent after the freezing centrifugation step and hence further cleanup is required. Using materials with large surfaces area for absorption of lipids have been employed since early 1970s. These materials include, Florisil, Lipid Removal Agent (LRA) media from Supelco, micro Cel E and Calflo E from Johns-Manville. Micro Cel E and Calflo E and LRA are synthetic calcium silicate while Florisil is a magnesium silicate with high specific surface area. [48,49] They can be applied to remove lipids either in sample preparation, solid phase extraction step or during sample clean-up step, with minimal effect on non-lipid chemicals. When food sample is mixed with these lipids absorbing materials, edible fat could be removed. Therefore it is common to conduct a clean-up step by solid phase extraction (SPE) nowadays. Both, conventional glass column packed with sorbent(s) and ready-to-use cartridges have been utilised and the common used phases are silica, Florisil, alumina and C18-bounded silica. Doong and Lee compared the cleaning efficiency of ready-to-use cartridge filled with three different adsorbents for shellfish extract. [50,51,52] Their results demonstrated that out of 14 OCPs tested, two were retained in the C18-cartridge. As for alumina and Florisil SPE, though all 14 pesticides tested could be recovered, Florisil provide better results in term of recoveries, repeatability and removal of interfering substances. Similarly, Hong et al., also 
showed that Florisil had better cleaning efficiency of fatty acids in fish extract when compared with C18. Besides, recoveries of some OCPs were poor with hexane as eluent and these more polar OCPs could be eluted out from the column with acetone. Bazlic et al., reported also that the quality of Florisil was important in avoiding possible interference and misinterpretation of results. Even though GC-MS was employed as the detection system, poor quality Florisil could introduce false positive results for lindane and dieldrin. [53,54] To sum up, the combination of sorbent(s) and eluting solvent(s) have to be chosen very carefully. Otherwise, some OCPs or their metabolites/derivatives would be lost during the clean-up step. [55,56,57] These OCPs could either break down or adhere to the sorbent material, leading to low or even no recovery. Finding of the optima clean-up conditions is an art itself. As the targeted OCPs might cover a wide range of polarities, it is quite difficult to find the best combination of SPE column material and eluting solvent, which permits recovering the polar OCPs (but leaving the polar interferents behind on the column), as well as recovering the non-polar OCPs (without eluting any residual oil present in the extract from the column).

\subsection{Detection techniques of OCPs}

A number of different selective detectors can be coupled with GC for analyzing OCPs, including electron capture detector (ECD), halogen specific detector (XSD), electrolytic conductivity detector (ELCD) and atomic emission detector (AED). GC-ECD is the most commonly used detection method with low detection limits. It is particularly useful for detecting halogen containing molecules. However, other organic molecules, such as aromatic compounds, would also give positive signal. Users have to confirm the presence of OCPs by another confirmative technique. Even though the above-mentioned selective detector can be used for quantification, it is unlike to fulfil the European Commission's stringest requirements as set for pesticides analysis. Confirmation with GC-hyphenated with mass spectrometric (MS) detector is normally required. Single quadrupole MS detector running in electron ionisation (EI) mode with target analytes monitored by selective ion monitoring (SIM) becomes a routine monitoring tool for OCPs nowadays. Since some OCPs are electronegative in nature, GC-MS detector under negative chemical ionisation mode with methane as reagent gas could provide better sensitivity. $[58,59,60,61]$ To further increase confidence in confirmative analysis, GC coupled with tandem Ms is one of suitable techniques. Besides providing a more definitive detection tool, tandem MS also decrease matrix interferences, improves selectivity and achieves higher signal-to-noise ratio and subsequently improves the detection limit. Both tandem-in-time (ion-trap) and tandem-in-space (triple quadrupoles) detector have been applied for OCPs residues analysis in different matrices. The determination of pesticides residues in the environment and in food is necessary for ensuring that human exposure to contaminants, especially by dietary intake, does not exceed acceptable level for health. Consequently, robust analytical methods have to be validated for carrying out both research and monitoring programmes, and thus for defining limitations and supporting enforcement of regulations. In this field, reproducible analytical methods are required to allow the effective separation, selective identification and accurate quantification of pesticides analyses at low levels in food-stuff including food of animal origin. 


\section{Aim of the research}

The aims of the present work were:

- To develop and optimise a simple extraction and clean-up method to quantify non-polar chlorinated compounds in high lipid containing samples (animal feed and subcutaneous fat bovine tissue).

- To validate a multiresidues method for the simultaneous determination of 20 OCPs by using GC-MS/MS in term of repeatability, precision, limit of detection (LOD), limit of quantification (LOQ) etc. The coupling of this detection mode is very useful for the analysis of these complex samples allowing the separation, identification, quantification and confirmation of a large number of pesticides at trace level.

- To monitor the OCPs level in animal feed samples used in bovine farm.

- To monitor the OCPs level in subcutaneous fat bovine tissue to asses and to verify the concentration phenomena of these persistent pollutants.

\section{Experimental}

\subsection{Feed and subcutaneous bovine fat samples}

25 feed samples used for bovine with different composition were obtained from intensive livestock farming. An example of feed mixture was shown in figure 1. 35 fat samples were obtained from bovine for slaughter (18-24 month age) and presented in figure 2.

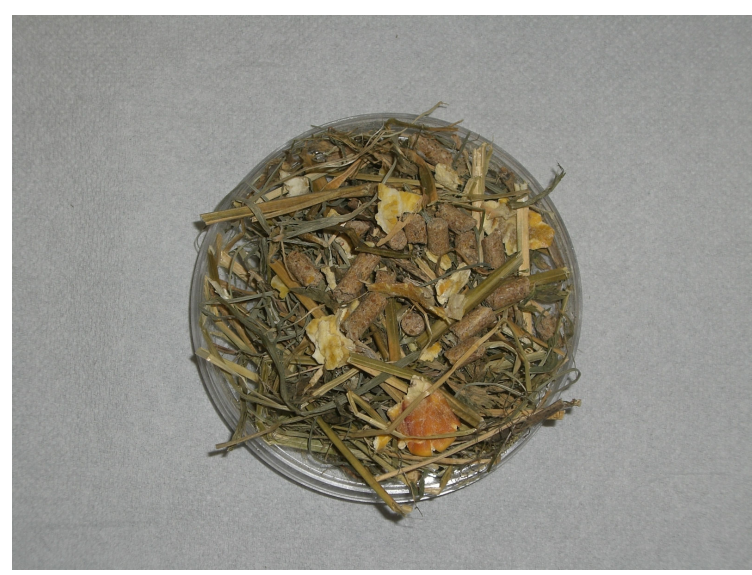

Figure 1. Feed sample mixture 


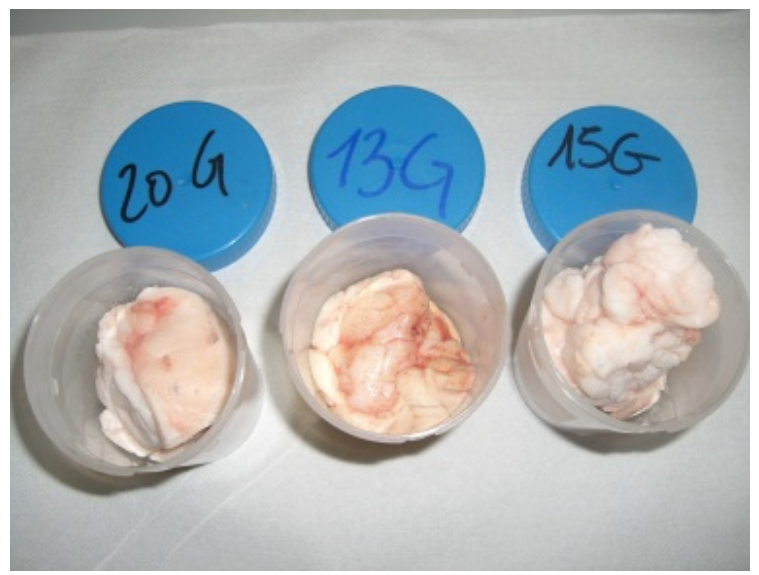

Figure 2. Subcutaneous fatty tissue sample

\subsection{Chemicals and reagents}

All OCPs were purchased from Supelco Inc.: mix 32094 and 32412 (Bellefonte, PA, USA). The figure 3 displays the structures of these OCPs considered in this study. Purities of pesticides standards were greater than $99 \%$. Working standard solution was prepared at concentration of $0.1-5 \mu \mathrm{g} \mathrm{mL} \mathrm{m}^{-1}$ by volume, dilution with acetone and hexane. Organic solvents (hexane, acetone and acetonitrile) were of pesticide residue analysis grade (Sigma Aldrich, USA). All glassware was cleaned with laboratory reagent, sequentially rinsed with distilled water, acetone and methanol and finally baked in a oven at $300{ }^{\circ} \mathrm{C}$. Distilled water was obtained with a Milli-Q system (Millipore, Bedford, MA, USA). For SPE, Florisil $5 \mathrm{~g}$ was purchased from Supelco.

\subsection{Equipments}

Ultrasonic bath (Branson) was used for the extraction of chlorinated pesticides form feed and fat samples. The generator of ultrasonic bath has an output of $150 \mathrm{~W}$ and a frequency of $35 \mathrm{kHz}$. Rotary evaporator (Buchi, Swiss) was used for the concentration of organic solvent. High intensity planetary mill Retsch (model MM 400, Retsch, GmbH, Retsch-Allee, Haan) was used to obtain representative aliquots of feed samples powder. 


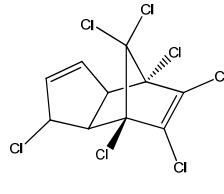

heptachlor

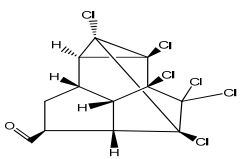

endrine aldehyde

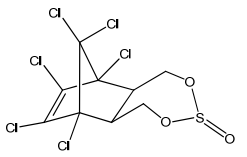

endosulfan II

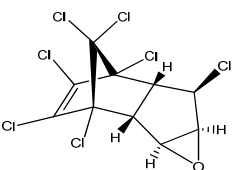

heptachlor epoxide

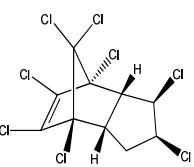

$\alpha$-chlordane

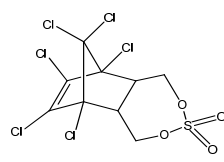

endosulfan sulfate

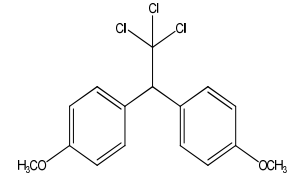

methoxychlor

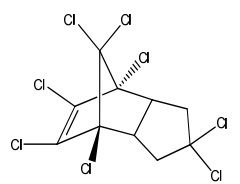

$\gamma$-chlordane

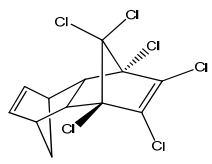

aldrin
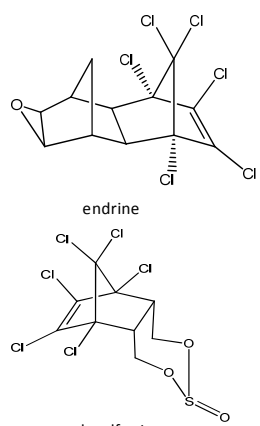

endosulfan I

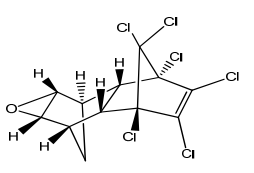

dieldrin
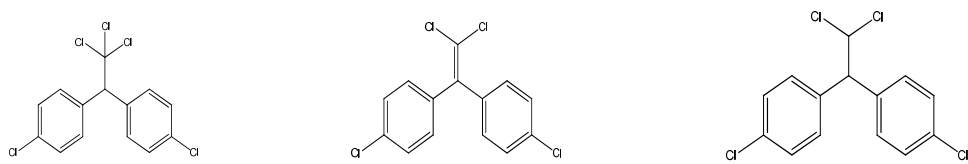

p-p'DDT<smiles>Cl[C@H]1[C@H](Cl)[C@H](Cl)[C@H](Cl)[C@@H](Cl)[C@H]1Cl</smiles>

p-p' DDE

p-p'DDD<smiles>O[C@H]1[C@@H](O)[C@H](Cl)[C@H](Cl)[C@H](Cl)[C@@H]1Cl</smiles>

$\alpha-\mathrm{HCH}$
$\beta-\mathrm{HCH}$<smiles>Cl[C@H]1[C@H](Cl)[C@H](Cl)[C@@H](Cl)[C@@H](Cl)[C@H]1Cl</smiles>

$\gamma-\mathrm{HCH}$ (lindane)<smiles>C[C@H]1[C@H](Cl)[C@@H](Cl)[C@H](Cl)[C@@H](Cl)[C@@H]1O</smiles>

$\delta$ - $\mathrm{HCH}$

Figure 3. Chemical structures of chlorinated pesticides investigated in this study (19 OCPs)

\subsection{Sample extraction, delipidation and clean-up procedure}

\subsubsection{Superfine Grinding (SFG) of feed sample}

In order to obtain a representative feed sample a superfine powder was prepared from feed using mechanical grinding-activation in an energy intensive vibrational mill. $50 \mathrm{~g}$ of different feed sample were ground in a high intensity planetary mill. The mill was vibrating at a frequency of $25 \mathrm{~Hz}$ for $4 \mathrm{~min}$ using two $50 \mathrm{~mL}$ jars with $20 \mathrm{~mm}$ stainless steel balls. Pre cooling of jars were carried out with liquid nitrogen in order to prevent temperature increasing during the grinding process. The speed differences between balls and jar resulted in the interaction of frictional and impact forces, releasing high dynamic energies. The interplay of all these forces resulted in the very effective energy input of planetary ball mills. The appli- 
cation of mechanochemistry deal with the physical changes of substances in all state of aggregation, for instance occurring with the combined action of pressure and shear in energyintensive grinding mills. Mechanochemical technology has been developed and applied in different fields (synthesis of superfine powder, surface modification and drug modification) and could represent a novel tool of research. $[62,63,64]$ The procedure is presented in Fig.4.

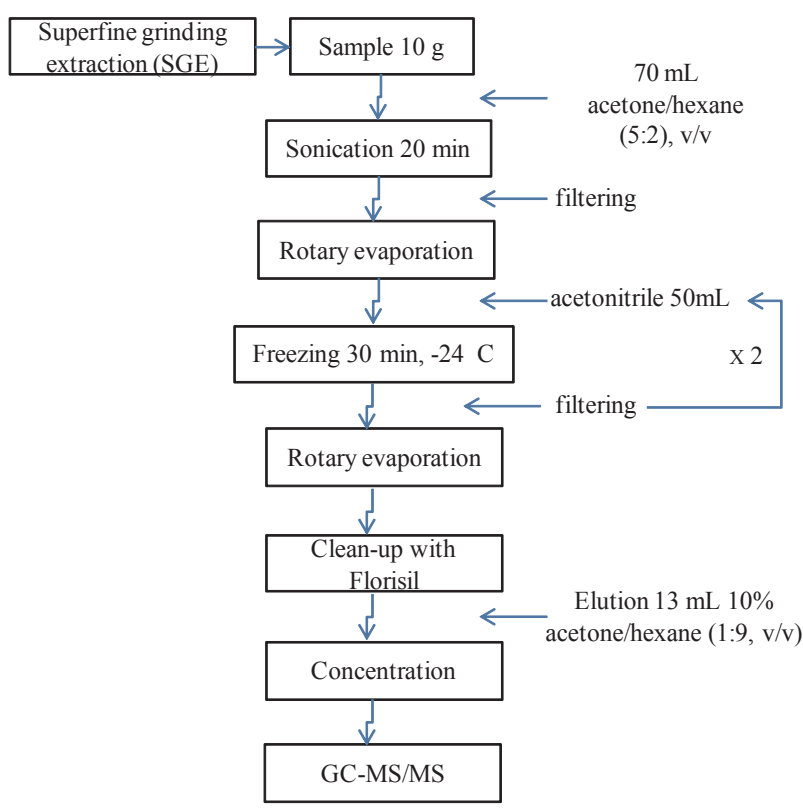

Figure 4. Analytical procedure for the extraction and purification of OCPsfrom feed and subcutaneous fatty tissue samples

\subsubsection{Samples extraction}

$10 \mathrm{~g}$ of subcutaneous fat tissue (homogenised in a cooled mixer) or feed sample finely grounded and prepared with the procedure described above (SFG) were extracted by ultrasonic agitation with a mixed solvent of $70 \mathrm{~mL}$ of acetone- $n$-hexane $(5: 2, \mathrm{v} / \mathrm{v})$ for $20 \mathrm{~min}$. Extract was filtered to remove traces of water with filter paper containing $5 \mathrm{~g}$ of sodium sulphate, and then transferred into a $250 \mathrm{~mL}$ round flask. The extraction was repeated one more time. Extracted solvent was dried and redissolved in $50 \mathrm{~mL}$ of acetonitrile that has low solubility for lipids. Acetonitrile extract was stored in the freezer at $-24^{\circ} \mathrm{C}$ for $30 \mathrm{~min}$ to freeze lipids. Most of the lipids were precipitated as pale yellow, condensed lump on glassware surface. Cold extract at $-24{ }^{\circ} \mathrm{C}$ was immediately filtered with filter paper to remove frozen lipids. The precipitated lipid on glassware surface was redissolved in $50 \mathrm{~mL}$ of acetonitrile to perform filtration again by same procedure. The filtered extracts were combined and concentrated to a final volume of $1 \mathrm{~mL}$ by a rotary evaporator to follow Florisil-SPE clean-up. 


\subsubsection{Sample clean-up}

The SPE cartridge was cleaned with $12 \mathrm{~mL}$ of n-hexane and air dried by positive pressure prior sample application. $5 \mathrm{~mL}$ of hexane were used to condition the cartridge. After sample loading, the cartridge was air dried for $10 \mathrm{~min}$. Desorption of the OCPs, which had been concentrated on the Florisil sorbent, was carried out using $13 \mathrm{~mL}$ of acetone- $n$-hexane (1:9, $\mathrm{v} / \mathrm{v}$ ) mixture at a flow of $1 \mathrm{~mL}$ min- 1 and collected in a $50 \mathrm{~mL}$ round flask. The eluate was then concentrated at $45{ }^{\circ} \mathrm{C}$ under nitrogen stream until just the disappearance of the last drop of solution. Finally, the residue was redissolved in $1 \mathrm{~mL}$ hexane Pestanal prior to its injection in GC-MS/MS system.

\subsection{GC-MS/MS analysis and detection}

A Varian GC 3800 gas chromatograph coupled to a Varian Saturn 2000 ion trap mass spectrometer was used for the analysis and detection of the OCPs. The gas chromatograph was equipped with a Rtx-5 fused-silica capillary column ( $30 \mathrm{~m} \times 0.25 \mathrm{~mm}$ i.d., $0.25 \mathrm{um}$ film thickness) obtained from Restek. Helium (purity 99,99\%) was the carrier gas at constant flow of 1 $\mathrm{mL} \mathrm{min}^{-1}$. The GC injector temperature was maintained at $280^{\circ} \mathrm{C}$. The oven program temperature was: initial temperature $120{ }^{\circ} \mathrm{C}$ increased by $5{ }^{\circ} \mathrm{C} \mathrm{min}{ }^{-1}$ to $280{ }^{\circ} \mathrm{C}$ and held for 10 $\mathrm{min}$. The ion trap spectrometer was operated in electron ionisation (EI) mode.

The ionization energy was set at $70 \mathrm{eV}$. The detector range was $\mathrm{m} / \mathrm{z} 40-650$. The transfer line and trap temperature were $250^{\circ} \mathrm{C}$ and $170{ }^{\circ} \mathrm{C}$ respectively.

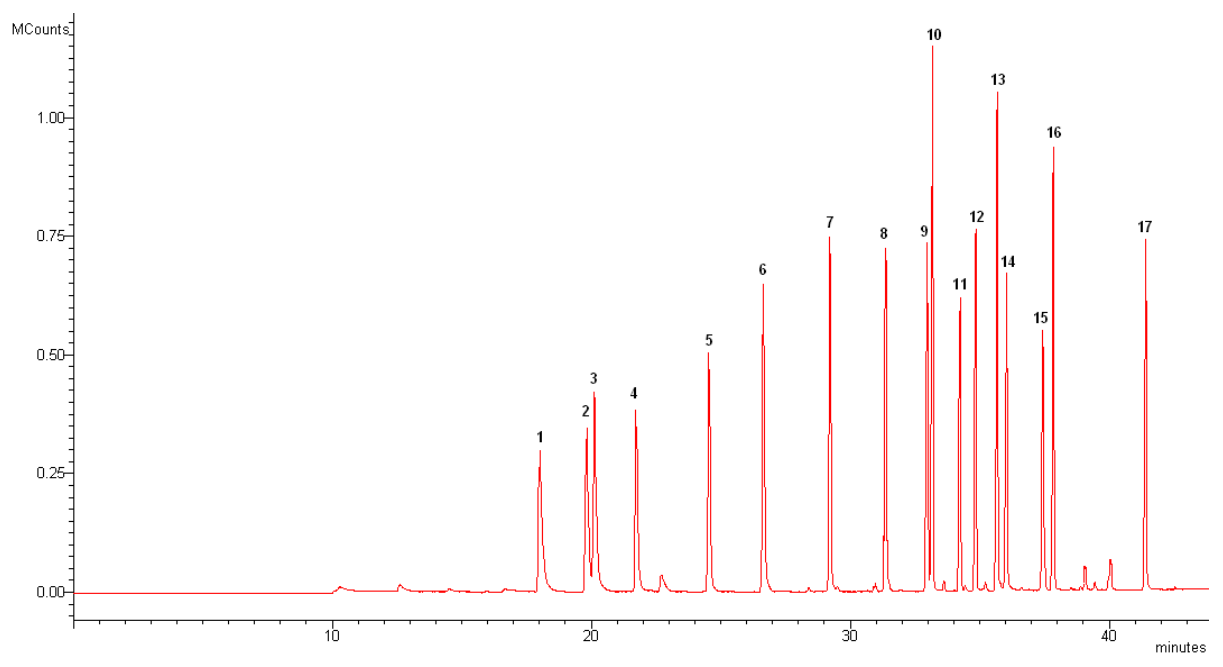

Figure 5. GC-MS chromatogram (TIC mode) of a standard OCPs mixture (MRL $0.5 \mathrm{mg} \mathrm{kg}^{-1}$ ) used in the present study. 1:a-HCH, 2: $\beta-\mathrm{HCH}, 3: \gamma-\mathrm{HCH}, 4: \delta-\mathrm{HCH}, 5: H e p t a c h l o r, 6: A l d r i n, 7:$ Heptachlor epoxide, 8:Endosulfan I, 9:Dieldrin, 10:p-p'DDE, 11:Endrin, 12:Endosulfan II, 13:p-p'DDD, 14:Endrin Aldheyde, 15: Endosulfan Sulphate, 16:pp'DDT, 17:Methoxychlor 


\section{Results and disussion}

\subsection{Key results about extraction and clean-up method}

Two extraction and clean-up methods have been developed, tested and optimised for the extraction of 20 OCPs from animal feed sample and subcutaneous fatty tissue samples from bovine.

Large amounts of lipids were extracted when n-hexane or acetone was used as extraction solvents. In general, complex mixtures of of several types of lipids were co-extracted during the extraction of chlorinated pesticides from biological sample. Triglycerides and sterol esters are the major components in meat fats.

The key point of the extraction method take advantage of significant difference of melting points between lipids (below about $40 \mathrm{C}$ ) and chlorinated pesticides (above $260 \mathrm{C}$ ), so that lipid components can be easily separated from chlorinated compounds. After extraction, lipids in organic extracts were precipitated as frozen at $-24 \mathrm{C}$ in the freezer, while chlorinated compounds were still dissolved in cold organic solvents. Thus frozen-lipids can be removed just by filtering extracts. During overall process, approximately $90 \%$ of lipids were eliminated without any significant loss of pesticides. After freezing-lipid filtration, the remaining interferences were successfully removed by a solid-phase (SPE) Florisil cartridge.

Sample clean-up was necessary for the removal of polar coextracted substances. Florisil cartridges have been employed for that purpose since that adsorbent has proved to be very efficient for the clean-up of food samples.

\subsection{Optimisation of MS/MS transitions}

From full scan spectra, the most intense higher mass precursor ions were selected for development of MRM method. For the most of the analytes these were the base peak ions in the mass spectra, but in some cases higher mass ions of lower intensity were selected to minimise the possibility of matrix interferences. Precursor ions were examined using different collision energies (automated method development) and the most intense product ions were selected for each precursor ion. The products ions for all OCPs determined in this study are summarise in table 1.

For quantification of the target analytes linear calibration curves for all pesticides over six calibration levels (0.005 mg kg-1 $\left.1.5 \mathrm{mg} \mathrm{kg}^{-1}\right)$ using a feed and fat blank samples were prepared taking also in consideration the MRLs levels for each compounds. In quantitative analysis one of the main problems is the suppression/enhancement of the analyte response caused by sample matrix components. Calibration curves were performed by using matrixmatched (in each matrix) because the feed and fat samples contain many compounds that are co-extracted in the extraction organic solvent. The use of Florisil-SPE tries to avoid matrix effect using a clean-up step, but this not eliminates completely the problem. A matrix effect on the analytical signal due to the matrix was noticed for most pesticides. 


\begin{tabular}{|c|c|c|c|c|c|c|}
\hline OCPs & $\begin{array}{l}\text { R.T. } \\
(\min )\end{array}$ & $\begin{array}{l}\text { Precursor ion } \\
(\mathrm{m} / \mathrm{z})\end{array}$ & $\begin{array}{l}\text { Product ions } \\
\qquad(\mathrm{m} / \mathrm{z})\end{array}$ & $\begin{array}{c}\text { Excitation } \\
\text { voltage (V) }\end{array}$ & $\begin{array}{l}\text { Linearity fat } \\
\qquad\left(r^{2}\right)\end{array}$ & $\begin{array}{l}\text { Linearity } \\
\text { Feed }\left(r^{2}\right)\end{array}$ \\
\hline $\mathrm{a}-\mathrm{BHC}$ & 18.01 & 181 & 109,142 & 1.0 & 0,9997 & 0,9974 \\
\hline Hexachlorobenzene & 18.41 & 286 & 214,249 & 1.0 & 0,9974 & 0,9951 \\
\hline$\beta-\mathrm{BHC}$ & 19.82 & 181 & 109,145 & 1.0 & 0,9980 & 0,9950 \\
\hline$Y-\mathrm{BHC}$ & 20.12 & 181 & 109,145 & 1.0 & 0,9984 & 0,9985 \\
\hline$\delta-\mathrm{BHC}$ & 21.73 & 181 & 109,145 & 1.0 & 0,9994 & - \\
\hline Heptachlor & 24.54 & 272 & 100,237 & 0.4 & 0,9987 & 0,9984 \\
\hline Aldrin & 26.63 & 293 & 220,255 & 0.8 & 0,9992 & 0,9951 \\
\hline Heptachlor epoxide & 29.21 & 353 & 263,334 & 0.7 & 0,9982 & 0,9977 \\
\hline -Clordane & 30.66 & 375 & 266,301 & 0.8 & 0,9944 & 0,9945 \\
\hline Endosulfan I & 31.37 & 241 & 170,260 & 0.9 & 0,9993 & 0,9978 \\
\hline a-Clordane & 31.61 & 375 & 266,301 & 0.8 & 0,9935 & 0,9910 \\
\hline Dieldrin & 32.96 & 263 & 193,228 & 0.7 & 0,9988 & 0,9979 \\
\hline$p-p^{\prime} D D E$ & 33.16 & 318 & 246,283 & 0.7 & 0,9974 & 0,9987 \\
\hline Endrin & 34.23 & 263 & 193,228 & 0.7 & 0,9982 & 0,9975 \\
\hline Endosulfan II & 34.84 & 241 & 170,260 & 0.9 & 0,9951 & 0,9973 \\
\hline$p-p^{\prime} D D D$ & 35.66 & 235 & 165,199 & 0.6 & 0,9958 & 0,9976 \\
\hline Endrin aldheyde & 36.03 & 345 & 243,279 & 0.7 & 0,9968 & - \\
\hline Endosulfan sulphate & 37.43 & 387 & 251,289 & 0.6 & 0,9988 & 0,9925 \\
\hline$p-p^{\prime}$ DDT & 37.84 & 235 & 165,199 & 0.6 & 0,9996 & 0,9971 \\
\hline Methoxychlor & 41.04 & 227 & 196,212 & 0.7 & 0,9982 & 0,9991 \\
\hline
\end{tabular}

Table 1. Summary of precursor ions and products ions selected for analysis of OCPs $n$ El mode and linearity for fat and feed sample calibration curves.

The linearity of the curves was studied for each pesticide considering the area of the peak relative to the internal standard. The calibration data are given in table 2, showing a good linearity of the response for all pesticides at concentration within the interval tested.

LOD and LOQ were evaluated taking into account the baseline noise variations in the chromatogram obtained from the analysis of blank feed and blank fat samples $(n=10)$. The LOD and LOQ were defined as the concentration of the analyte that produced a signal-to-noise ratio of 3 times and 10 times the standard deviation respectively above the blank signal. Table 2 shows the values in $\mathrm{mg} \mathrm{kg}^{-1}$ of feed and fat sample calculated with blank sample extracts. The values are similar to those obtained by other authors for the LOD and LOQ in feed animal samples. LOD and LOQ values for subcutaneous fat sample are not present in literature. Our results are very similar to that obtained in fish muscle and meat. 


\begin{tabular}{|c|c|c|c|c|c|c|}
\hline \multirow[b]{2}{*}{ OCPs } & \multicolumn{3}{|c|}{ Subcutaneous fat tissue } & \multicolumn{3}{|c|}{ Animal feed } \\
\hline & $\begin{array}{c}\mathrm{MRL}^{*} \\
\left(\mathrm{mg} \mathrm{kg}^{-1}\right)\end{array}$ & $\begin{array}{c}\text { LOD } \\
\left(\mathrm{mg} \mathrm{kg}^{-1}\right)\end{array}$ & $\begin{array}{c}\text { LOQ } \\
\left(\mathrm{mg} \mathrm{kg}^{-1}\right)\end{array}$ & $\begin{array}{c}\mathrm{MRL}^{\star *} \\
\left(\mathrm{mg} \mathrm{kg}^{-1}\right)\end{array}$ & $\begin{array}{c}\text { LOD } \\
\left(\mathrm{mg} \mathrm{kg}^{-1}\right)\end{array}$ & $\begin{array}{c}\text { LOQ } \\
\left(\mathrm{mg} \mathrm{kg}^{-1}\right)\end{array}$ \\
\hline $\mathrm{a}-\mathrm{BHC}$ & 0.5 & 0.007 & 0.024 & 0.02 & 0.002 & 0.016 \\
\hline Hexachlorobenzene & 0.2 & 0.007 & 0.026 & 0.01 & 0.003 & 0.011 \\
\hline$\beta-\mathrm{BHC}$ & 0.1 & 0.012 & 0.041 & 0.01 & 0.003 & 0.010 \\
\hline $\mathrm{Y}-\mathrm{BHC}$ & 0.02 & 0.001 & 0.006 & 0.2 & 0.012 & 0.04 \\
\hline$\delta-\mathrm{BHC}$ & 0.5 & 0.007 & 0.023 & 0.02 & - & - \\
\hline Heptachlor & 0.2 & 0.004 & 0.010 & 0.01 & 0.001 & 0.005 \\
\hline Aldrin & 0.5 & 0.003 & 0.010 & 0.01 & 0.004 & 0.015 \\
\hline Heptachlor epoxide & 0.2 & 0.002 & 0.008 & 0.01 & 0.002 & 0.009 \\
\hline Y-Clordane & 0.05 & 0.005 & 0.019 & 0.02 & 0.003 & 0.013 \\
\hline Endosulfan I & 0.05 & 0.003 & 0.012 & 0.1 & 0.007 & 0.024 \\
\hline a-Clordane & 0.05 & 0.005 & 0.019 & 0.02 & 0.005 & 0.017 \\
\hline Dieldrin & 0.2 & 0.002 & 0.008 & 0.01 & 0.002 & 0.007 \\
\hline$p-p^{\prime} D D E$ & 1 & 0.001 & 0.005 & 0.05 & 0.003 & 0.012 \\
\hline Endrin & 0.05 & 0.002 & 0.007 & 0.01 & 0.004 & 0.013 \\
\hline Endosulfan II & 0.05 & 0.003 & 0.010 & 0.1 & 0.004 & 0.016 \\
\hline$p-p^{\prime}$ DDD & 1 & 0.002 & 0.008 & 0.05 & 0.002 & 0.008 \\
\hline Endrin aldehyde & 0.05 & 0.003 & 0.011 & 0.02 & - & - \\
\hline Endosulfan sulphate & 0.05 & 0.002 & 0.006 & 0.1 & 0.007 & 0.023 \\
\hline$p-p^{\prime}$ DDT & 1 & 0.004 & 0.001 & 0.05 & 0.006 & 0.02 \\
\hline Methoxychlor & 0.01 & 0.002 & 0.008 & 0.5 & 0.002 & 0.007 \\
\hline
\end{tabular}

${ }^{*}=$ MRLs of EU regulation guidelines (CE 32/2002); ${ }^{* *}=$ MRLs of EU regulation guidelines (CE 396/2005)

Table 2. MRLs, limits of detection (LOD) and limits of quantification (LOQ) for OCPs in fat and feed samples.

\subsection{Occurrence of OCPs in animal feed samples and subcutaneous fat samples}

The OCPs residues may concentrate in the adipose tissue and in blood serum of animals leading to environmental persistence, bioconcentration and biomagnifications through the food chain. Pesticides contamination of meat as well as chicken resulting from feeding a diet containing a low concentration of pesticides is a well established fact. [63,64] OCPs residues in feed may be ingested bi herbivores and eventually find their way into the animal body which ultimately results in contamination of milk, meat eggs, etc. consumed by human being. $[65,66]$

The most pesticides detected in animal feed were p-p' DDT, heptachlor followed by lindane, methoxychlor and aldrin. The frequency of detection is presented in figure. 6 . 
In subcutaneous fat sample the most detected OCPs were heptachlor, hexachlorobenzene detected in all samples followed by $\mathrm{p}-\mathrm{p}^{\prime}$ DDE, $\mathrm{p}-\mathrm{p}^{\prime} \mathrm{DDT}$, methoxychlor, lindane and $\mathrm{p}-\mathrm{p}^{\prime}$ DDD as shown in figure 7. Aldrin was detected both in feed samples and animal fat. The presence of aldrin in meat indicates the need for concern from the public health point of view because of its much higher toxicity than other OCPs. $[67,68]$ These results are in accordance with other author that found HCHS and DDTs the most compounds detected in meat samples. In general, it was observed that the p-p' isomers of DDE, DDT and DDDwere detected in samples. All detected pesticides in feed samples and fat samples did not exceed the MRLs established by the European Union for each compounds (Fig 8, 9). The concentration of detected pesticides in the samples are summarised in table 3.

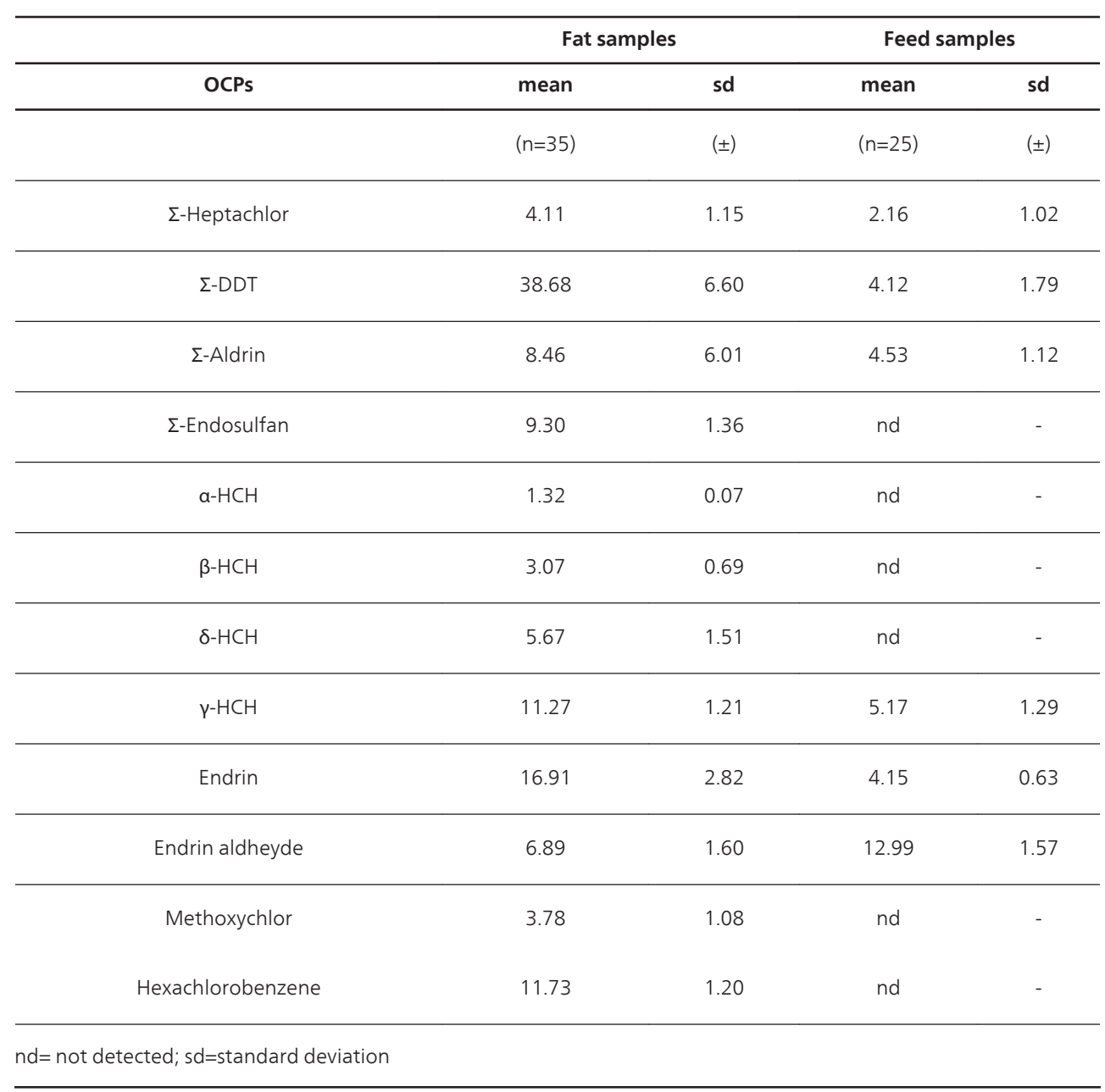

Table 3. Mean organochlorine residues levels $\left(\mu \mathrm{g} \mathrm{kg}^{-1}\right)$ in subcutaneous fat and feed samples 


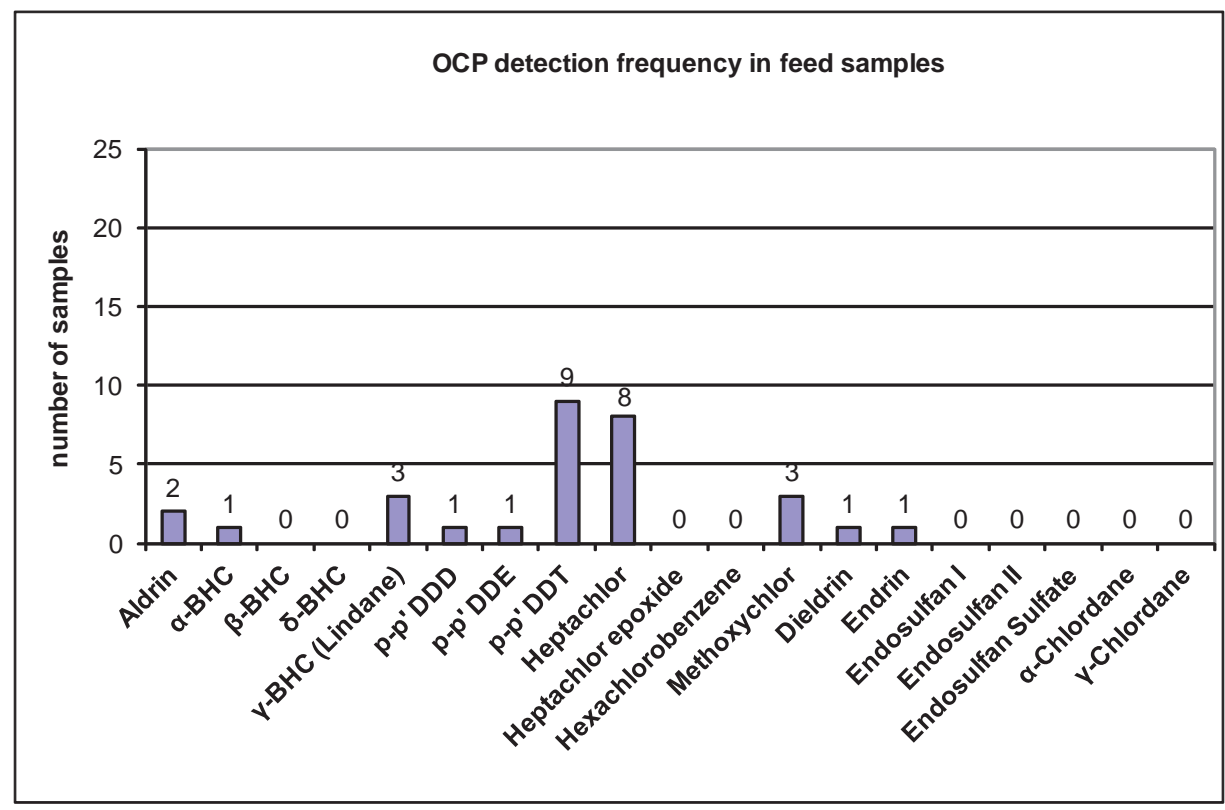

Figure 6. OCPs detection frequency in feed samples

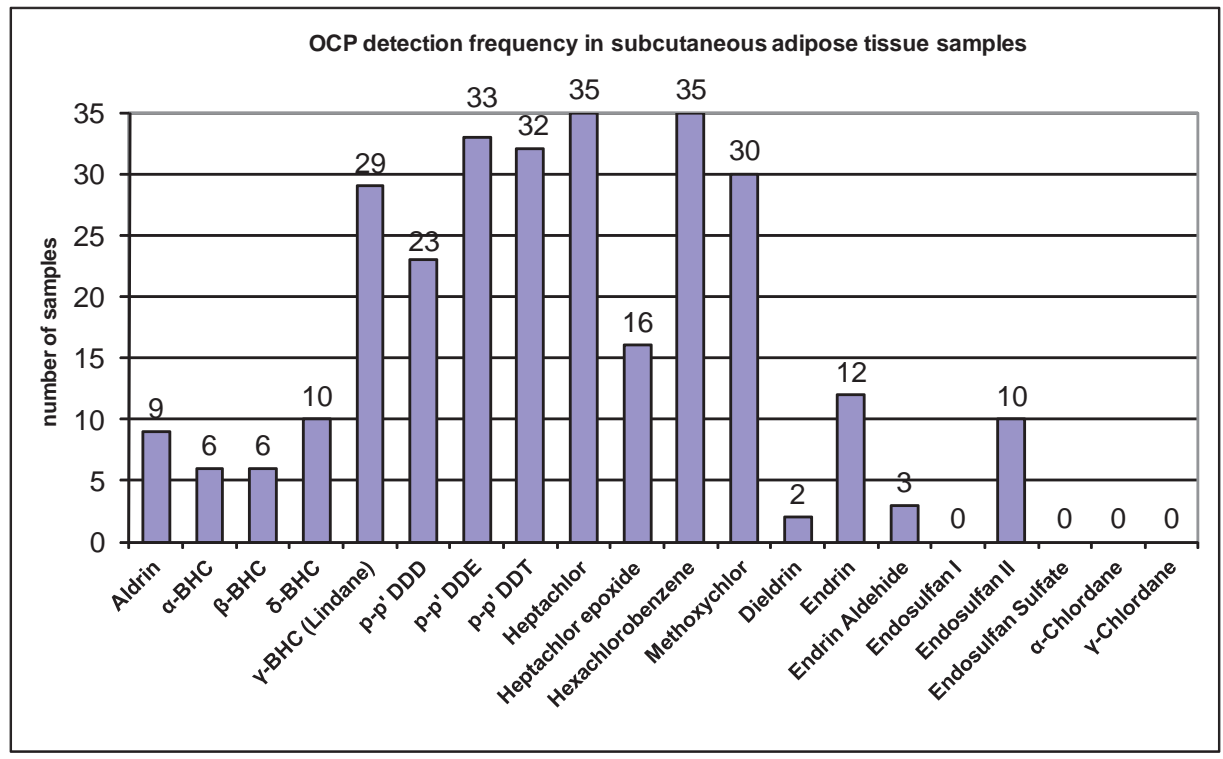

Figure 7. OCPs detection frequency in subcutaneous fat samples 


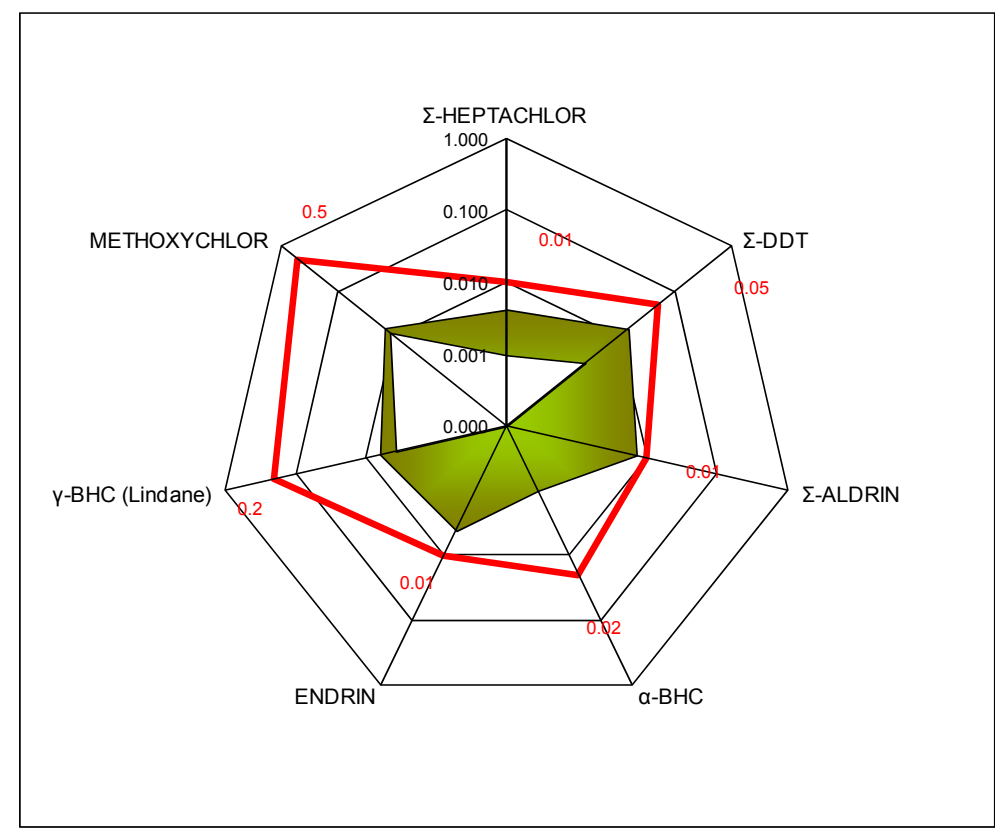

Figure 8. Radar plot of detected OCPs content in ( $\mathrm{mg} \mathrm{kg}^{-1}$ ) feed samples in relation to MRLs (red line)

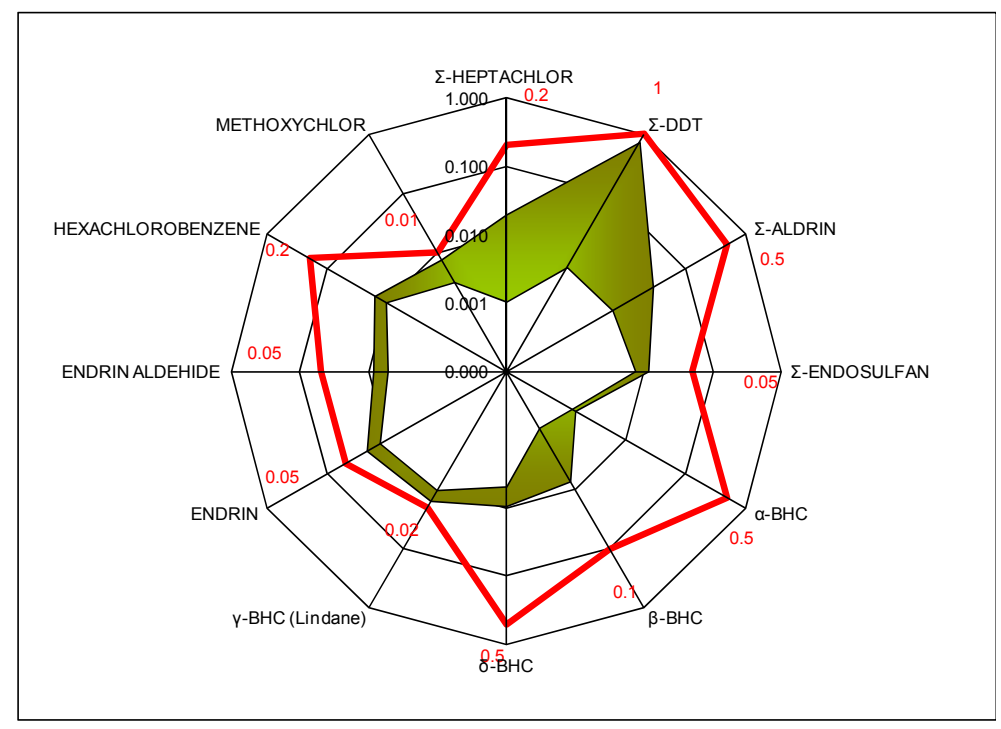

Figure 9. Radar plot of detected OCPs content $\left(\mathrm{mg} \mathrm{kg}^{-1}\right)$ in subcutaneous fat tissue samples in relation to MRLs (red line) 
In conclusion a rapid extraction, freezing lipid filtration and GC-MS/MS measurement methods were developed and used to measure chlorinated pesticide levels in animal feed sample and subcutaneous fatty tissue in order to assess the possible concentration phenomena of these persistent compounds. The freezing lipid filtration combined with Florisil-SPE cartridge enabled efficient removal of lipids extracted from feed and fat samples without significant loss of pesticides. Hence, the method offers a rapid and valid screening tool with high sensitivity for determination of organochlorine pesticides based on GC-MS/MS detection.

The subcutaneous fatty bovine tissue has been confirmed as target organ able to concentrate pesticides with lipophilic behaviour like organochlorine residues. The feed could also represent a possible source for contamination of OCPs through the food-chain. Therefore, the determination of pesticides residues in feed and food is today necessary for ensuring that human exposure to contaminants, especially by dietary intake, does not exceed acceptable levels for heath. One analytical challenge in the food safety is to present reliable results with respect to official guidelines.

\section{Author details}

S. Panseri ${ }^{1}$, P.A. Biondi ${ }^{2}$, D. Vigo ${ }^{1}$, R. Communod ${ }^{1}$ and L. M. Chiesa ${ }^{1}$

1 Department of Veterinary Science and Public Health, Faculty of Veterinary Medicine, University of Milan, Milan, Italy

2 Department of Department of Health, Animal Science and Food Safety, Faculty of Veterinary Medicine, University of Milan Milan, Italy

\section{References}

[1] Benbrook C.M. Organochlorine Residues Pose Surprisingly High Dietary Risks. J. Epidemiol. Community Health 2002; 56822.

[2] Lehotay S.J., Mastovska K., Yun S.J. Evaluation of Two Fast And Easy Methods For Pesticide Residue Analysis In Fatty Food Matrices. J. Aoac Int. 2005; 88630.

[3] Qiu X., Zhu T., Yao B., Hu, J. Hu, S. Contribution of Dicofol To The Current Ddt Pollution In China. Environ.Sci. Technol. 2005; 394385.

[4] Bilrha, H., Roy, R., Moreau, B., Belles-Isles, M., Dewailly, E., Ayotte, P.,. In vitro activation of cord blood mononuclear cells and cytokine production in a remote coastal population exposed to organochlorines and methyl mercury. Environ. Health Perspect. 2003; 111. 
[5] Lavoie E. T. and Grasman, K. A. Effects of in ovo exposure to PCBs 126 and 77 on mortality, deformities and post-hatch immune function in chickens, J. Toxicol. Environ. Health, Part A 2007, 70547.

[6] Bernhoft, A. Skaare J. U. and Wiig O. Possible immunotoxic effects of organochlorines in polar bears (Ursus maritimus) at Svalbard, J. Toxicol. Environ. Health, Part A, 2000; 59561.

[7] Repetto R. and Baliga, S. S. Pesticides and immunosuppression: the risks to public health, Health Policy Plan., 1997; 1297.

[8] Ahlborg, U. G. Lipworth L.and Titus-Ernstoff, L. Organochlorine compounds in relation to breast cancer, endometrial cancer, and endometriosis: an assessment of the biological and epidemiological evidence, Crit. Rev. Toxicol., 1995; 25463.

[9] Hardell L, Liljegren G, Lindstrom G. Increased concentrations of chlordane in adipose tissue from non-Hodgkin's lymphoma patients compared with controls without a malignant disease. Int J Oncol 1996; 9.

[10] Morgan D P, Roan C C.. Absorption, storage, and metabolic conversion of ingested DDT and DDT metabolites in man. Arch Environ Health 1971; 22301.

[11] Cocco P, Brennan P, Ibba A, de Sanjose LS, Maynadie M, Nieters A, et al. Plasma polychlorobiphenyl and organochlorine pesticide level and risk of major lymphoma subtypes. Occup Environ Med 2008; 65132.

[12] Bocquene G., Franco A. Pesticide Contamination Of The Coastline Of Martinique. Mar. Pollut. Bull. 2005; 51612.

[13] Gilbert-Lopez B., Garcia-Reyes J.F., Molina-Díaz A. Sample Treatment And Determination Of Pesticide Residues In Fatty Vegetable Matrices: A Review. Talanta 2009; 79 109.

[14] Ledoux, M. Analytical Methods Applied To The Determination Of Pesticide Residues In Foods Of Animal Origin. A Review Of The Past Two Decades. J. Chromatogr. A 2011; 12181021.

[15] Veierov, D. Aharonson, N. Improved Cleanup Of Large Lipid Samples For Electron Capture Gas Chromatographic Quantitation And Gas Chromatographic-Mass Spectrometric Confirmation Of Organochlorine Residues. J. Assoc. Off. Anal. Chem. 1980; 63202.

[16] S.J. Young, L.R. Kamps. Gas-Liquid Chromatographic Determination Of Nonpolar Organochlorine Pesticide Residues In A Crude Vegetable Oil And Its Refinery ByProducts. J. Assoc. Off. Anal. Chem. 1982; 65916.

[17] Luke, M.A. Forberg J.E, Masumoto, H.T. Extraction And Cleanup Of Organochlorine, Organophosphate, Organonitrogen, And Hydrocarbon Pesticides In Produce For Determination By Gas-Liquid-Chromatography. J. Assoc. Off. Agric. Chem. 1975; 58 1020. 
[18] Stefanelli, P. Santilio, A. Cataldi, L. Dommarco, R. Multiresidue Analysis Of Organochlorine And Pyrethroid Pesticides In Ground Beef Meat By Gas ChromatographyMass Spectrometry. J. Environ. Sci. Health B 2009; 44350.

[19] Sannino, A. Mambriani, P. Bandini, M. Bolzoni, L. Multiresidue Method For Determination Of Organochlorine Insecticides And Polychlorinated Biphenyl Congeners In Fatty Processed Foods. J. Aoac Int. 1996; 791434.

[20] Lazaro, R. Herrera, A. Arino, A.A. Conchello, M.P.S. Bayarri, J. Organochlorine Pesticide Residues In Total Diet Samples From Arago'N (Northeastern Spain). Agric. Food Chem. 1996; 442742.

[21] Patel, K. Fussell R.J., Hetmanski, M. Goodall, D.M. Keely, B.J. Evaluation Of Gas Chromatography-Tandem Quadrupole Mass Spectrometry For The Determination Of Organochlorine Pesticides In Fats And Oils. J. Chromatogr. A. 2005; 1068289.

[22] Schenck, F.J. Donoghue, D.J. Determination Of Organochlorine And Organophosphorus Pesticide Residues In Eggs Using A Solid Phase Extraction Cleanup. Agric. Food Chem. 2000; 486412.

[23] Muralidharan, S. Dhananjayan, V. Risebrough, R. Prakash, V. Jayakumar, R. Bloom, P.H. Persistent Organochlorine Pesticide Residues In Tissues And Eggs Of WhiteBacked Vulture, Gyps Bengalensis From Different Locations In India. Bull. Environ. Contam. Toxicol. 2008; 81561.

[24] Ghidini, S. Zanardi E., Battaglia A., Varisco G., Ferretti, E. Campanini, G. Chizzolini R. Comparison Of Contaminant And Residue Levels In Organic And Conventional Milk And Meat Products From Northern Italy. Food Addit. Contam. 2005; 229.

[25] Bennett, D.A. Chung, A.C. Lee S.M. Multiresidue Method For Analysis Of Pesticides In Liquid Whole Milk. J. Aoac Int. 1997; 801065.

[26] Hong, J. Kima H.Y., Kim, D.G. Seo, J. Kimb, K.J.Rapid Determination Of Chlorinated Pesticides In Fish By Freezing-Lipid Filtration, Solid-Phase Extraction And Gas Chromatography-Mass Spectrometry. J. Chromatogr. A 2004; 103827.

[27] Garridofrenich, A. Martinezvidal, J. Cruzsicilia, A. Gonzalezrodriguez, M. Plazabolanos P. Multiresidue Analysis Of Organochlorine And Organophosphorus Pesticides In Muscle Of Chicken, Pork And Lamb By Gas Chromatography-Triple Quadrupole Mass Spectrometry. Anal. Chim. Acta 2006; 55842.

[28] Fillion, J. Sauve, F. Selwyn, J. Multiresidue Method For The Determination Of Residues Of 251 Pesticides In Fruits And Vegetables By Gas Chromatography/Mass Spectrometry And Liquid Chromatography With Fluorescence Detection. Aoac Int. 2000; 83698.

[29] Lehotay, S.J. Analysis Of Pesticide Residues In Mixed Fruit And Vegetable Extracts By Direct Sample Introduction/Gas Chromatography/Tandem Mass Spectrometry. J. Aoac Int. 2000; 83 680. 
[30] Cunha, S.C. Lehotay, S.J. Mastovska, K. Fernandes, J.O. Beatriz, M. Oliveira, P.P. Evaluation Of The Quechers Sample Preparation Approach For The Analysis Of Pesticide Residues In Olives. J. Sep. Sci. 2007; 30620.

[31] Organochlorine Pesticide Residuals In Chickens And Eggs At A Poultry Farm In Beijing, China; Tao, S. Liu, W.X. Li, X.Q. Zhou, D.X. Li, X. Yang, Y.F. Yue,D.P., Coveney, R.M. Environ. Pollut. 2009; 157497.

[32] Distribution Of Organochlorine Pesticides And Alpha-Hch Enantiomers In Pork Tissues. Chemosphere; Covaci, A. Gheorghe, A Schepens,. P. Chemosphere 2004; 56757.

[33] Doong, R.A. Lee, C.Y. Determination Of Organochlorine Pesticide Residues In Foods Using Solid-Phase Extraction Clean-Up Cartridges. Analyst 1999; 1241287.

[34] Muralidharan, S. Dhananjayan, V. Jayanthi. Organochlorine Pesticides In Commercial Marine Fishes Of Coimbatore, India And Their Suitability For Human Consumption. P. Environ. Res. 2009; 10915.

[35] Campos, A. Lino, C.M. Cardoso, S.M. Silveira, M.I. Organochlorine Pesticide Residues In European Sardine, Horse Mackerel And Atlantic Mackerel From Portugal. Food Addit. Contam. 2005; 22642.

[36] Fidalgo-Used, N. Centineo, G. Blanco-Gonzalez, E. Sanz-Medel, A. Solid-Phase Microextraction As A Clean-Up And Preconcentration Procedure For Organochlorine Pesticides Determination In Fish Tissue By Gas Chromatography With Electron Capture Detection. J. Chromatogr. A 2003; 101735.

[37] Hopper, M.L. Automated One-Step Supercritical Fluid Extraction And Clean-Up System For The Analysis Of Pesticide Residues In Fatty Matrices. J. Chromatogr. A 1999; 84093.

[38] Argauer, R.J. Eller, K.I. Pfeil, R.M Brown, R.T. Determining Ten Synthetic Pyrethroids In Lettuce And Ground Meat By Using Ion Trap Mass Spectrometry And Electron-Capture Gas Chromatography. J. Agric. Food Chem. 1997; 45180.

[39] Ashraf-Khorassani, M. Taylor, L.T. Schweighardt, F.K. Development Of A Method For Extraction Of Orgaochlorine Pesticides From Rendered Chicken Fat Via Supercritical Fluoroform. J. Agric. Food Chem. 1996; 443540.

[40] Saito, K. A. Sjodin, C.D. Sandau, M.D. Davis, H. Nakazawa, Y. Matsuki, D.G. Patterson Jr., Development Of A Accelerated Solvent Extraction And Gel Permeation Chromatography Analytical Method For Measuring Persistent Organohalogen Compounds In Adipose And Organ Tissue Analysis Chemosphere 2004; 57373.

[41] Suchan, P. Pulkrabova, J. Hajslova, J. Kocourek, V. Pressurized Liquid Extraction In Determination Of Polychlorinated Biphenyls And Organochlorine Pesticides In Fish Samples. Anal. Chim. Acta 2004 520; 193.

[42] Weichbrodt, M. Vetter, W. Luckas, B. Microwave-Assisted Extraction And Accelerated Solvent Extraction With Ethyl Acetate-Cyclohexane Before Determination Of Or- 
ganochlorines In Fish Tissue By Gas Chromatography With Electron-Capture Detection. J. Aoac Int. 2000; 831334.

[43] Vetter, W. Weichbrodt, M. Hummert, K. Glotz, D. Luckas, B. Combined MicrowaveAssisted Extraction And Gel Permeation Chromatography For The Determination Of Chlorinated Hydrocarbons In Seal Blubber And Cod Livers; Chemosphere 1998; 37 2439 .

[44] Wilkowska, A.M. Biziuk, M. Rapid Method For The Determination Of Organochlorine Pesticides And Pcbs In Fish Muscle Samples By Microwave-Assisted Extraction And Analysis Of Extracts By Gc-Ecd. J. Aoac Int. 2010; 931987.

[45] Barriada-Pereira, M. Iglesias-Garcia, I. Gonzalez-Castro, M.J. Muniategui- Lorenzo, S. Lopez-Mahia, Prada-Rodriguez P.D., Pressurized Liquid Extraction And MicrowaveAssisted Extraction In The Determination Of Organochlorine Pesticides In Fish Muscle Samples. J. Aoac Int. 2008; 91174.

[46] Karasova, G. Brandsteterova, E. Lachova, Matrix Solid Phase Dispersion As An Effective Preparation Method For Food Samples And Plants Before Hplc Analysis. M. Czech J. Food Sci. 2003; 21219.

[47] Yagüe, C Bayarri,. S. Lazaro, R. Conchello, P. Arino, A. Herrera, A. Multiresidue Determination Of Organochlorine Pesticides And Polychlorinated Biphenyls In Milk By Gas Chromatography With Electron-Capture Detection After Extraction By Matrix Solid-Phase Dispersion. J. Aoac Int. 2001; 841561.

[48] Yagüe, C. Herrera, A. Arino, A. Lazaro, R. Bayarri, S.. Conchello, P. Rapid Method For Trace Determination Of Organochlorine Pesticides And Polychlorinated Biphenyls In Yogurt. J. Aoac Int. 2002; 851181.

[49] Schenck, F.J. Wagner, R. Screening-Procedure For Organochlorine And Organophosphorus Pesticide-Residues In Milk Using Matrix Solid-Phase Dispersion (Mspd) Extraction And Gas-Chromatographic Determination. Food Addit. Contam. 1995; 12 535.

[50] Schenck, F.J. Calderon, L. Saudarg, D.E. Florisil Solid-Phase Extraction Cartridges For Cleanup Of Organochlorine Pesticide Residues In Foods. J. Aoac Int. 1996; 791454.

[51] Lott, H.M. Barker, S.A. Matrix Solid-Phase Dispersion Extraction And Gas-Chromatographic Screening Of 14 Chlorinated Pesticides In Oysters (Crassostrea-Virginica). J. Aoac Int. 1993; 7667.

[52] Long, A.R. Soliman, M.M. Barker, S.A. Matrix Solid-Phase Dispersion (Mspd) Extraction And Gas-Chromatographic Screening Of 9 Chlorinated Pesticides In Beef Fat. J. Assoc. Off. Anal. Chem. 1991; 74493.

[53] Long, A.R. Crouch, M.D. Barker, S.A. Multiresidue Matrix Solid-Phase Dispersion (Mspd) Extraction And Gas-Chromatographic Screening Of 9 Chlorinated Pesticides 
In Catfish (Ictalurus-Punctatus) Muscle-Tissue. J. Assoc. Off. Anal. Chem. 1991; 74 667.

[54] Valsamaki, V.I. Boti, V.I. Sakkas, V.A. Albanis, T.A. Determination Of Organochlorine Pesticides And Polychlorinated Biphenyls In Chicken Eggs By Matrix Solid Phase Dispersion. Anal. Chim. Acta 2006 195; 573-574.

[55] Rogers, W.M. The Use Of A Solid Support For The Extraction Of Chlorinated Pesticides From Large Quantities Of Fats And Oils. J. Assoc. Off. Anal. Chem. 1972; 55 1053.

[56] Porter, M.L. Burke, J.A. An Isolation And Cleanup Procedure For Low Levels Of Organochlorine Pesticide Residues In Fats And Oils. J. Assoc. Off. Anal. Chem. 1973; 56 733.

[57] Bong, R.L. Determination Of Hexachlorobenzene And Mirex In Fatty Products. J. Assoc. Off. Anal. Chem. 1975; 58557.

[58] Goodspeed, D.P. Chestnut, L.I. Determining Organohalides In Animal Fats Using Gel-Permeation Chromatographic Cleanup - Repeatability Study. J. Assoc. Off. Anal. Chem. 1991; 74388.

[59] Bazulic, D. Sapunar-Postruznik, J. Bilic, Arh. S. Significance Of The Quality Of Florisil In Organochlorine Pesticide Analysis; Hig. Rada Toksikol. 49 (1998) 319.

[60] Beyer, A. Biziuk, M. Comparison Of Efficiency Of Different Sorbents Used During Clean-Up Of Extracts For Determination Of Polychlorinated Biphenyls And Pesticide Residues In Low-Fat Food. Food Res. Int. 2010; 43831.

[61] Determination Of Pesticides In Composite Dietary Samples By Gas Chromatography/Mass Spectrometry In The Selected Ion Monitoring Mode By Using A Temperature-Programmable Large Volume Injector With Preseparation Column. Rosenblum, L. Hieber, T. Morgan, J. J. Aoac Int. 2001; 84891.

[62] Xie J, Shi L, Zhu X, Wang P, Zhao Y and Su W, Mechanochemical-assisted efficient extraction of ruitn from Hibiscus mutabilis L. Innovative Food Science and Emerging Technologies. 2011; 12: 1446.

[63] Liu Y, Jin LJ, Li XY and Xu YP, Application of Mechanochemical Pretreatment to Aqueous Extraction of Isofraxidin from Eleutherococcus Senticosus. Ind. Eng. Chem. Res.: 2007; 466584.

[64] Zhu XY, Lin HM, Chen X, Xie J and Wang P, Mechanochemical-assisted Extraction and antioxidant Activities of Kaempferol Glycosides from Camellia oleifera Abel. Meal. J. Agr. Food Chem. 2011; 3986.

[65] Fillion, J. Hindle, R. Lacroix, M. Selwyn, J. Multiresidue Determination Of Pesticides In Fruit And Vegetables By Gas Chromatography Mass-Selective Detection And Liquid Chromatography With Fluorescence Detection. J. Aoac Int. 1995; 781252. 
[66] Guan, H. Brewer, W.E. Morgan, S.L. New Approach To Multiresidue Pesticide Determination In Foods With High Fat Content Using Disposable Pipette Extraction (Dpx) And Gas Chromatography-Mass Spectrometry (Gc-Ms). J. Agric. Food Chem. 2009; 5710531.

[67] Gillespie, A.M. Walters, S.M. Semi-Preparative Reverse Phase Hplc Fractionation Of Pesticides From Edible Fats And Oils. J. Liq. Chromatogr. 1989; 121687.

[68] Van Der Hoff G.R., Van Beuzekom, A.C. Brinkman, U.A. Baumann, R.A. Van Zoonen, P. Determination Of Organochlorine Compounds In Fatty Matrices - Application Of Rapid Off-Line Normal-Phase Liquid Chromatographic Clean-Up. J. Chromatogr. A 1996; 754487. 
